Article

\title{
A Review on Handicap Sections and Situations to Improve Driving Safety of Automated Vehicles
}

\author{
Chang-Gyun Roh $(1)$ and I-Jeong Im * $*$ \\ Smart Mobility Research Center, Department of Future Technology and Convergence Research, Korea Institute \\ of Civil Engineering and Building Technology, Gyeonggi 10223, Korea; rohcg@kict.re.kr \\ * Correspondence: limjay78@kict.re.kr
}

Received: 18 May 2020; Accepted: 6 July 2020; Published: 8 July 2020

check for updates

\begin{abstract}
An automated vehicle performs self-driving by utilizing information gathered through sensors attached to the vehicle. Sensor accuracy is thus mentioned as the major technology for enhancing driving safety. However, since urban centers are replete with sections and situations that handicap driving such as sensor recognition limitations and failures, it is necessary to conduct a study that prepares for driving handicaps. As such, this study aims to derive the sections and situations where driving safety is depreciated and review those problems via an analytic hierarchy process (AHP) analysis on driving handicap factors. The analysis result showed that the importance of these handicap situations is high, and it was confirmed that it is necessary to first review off-road sections, environmental factors (heavy rain or snow), merge sections, and sections with poor lane conditions. The result of this research has significance in reviewing road sections and potential situations that require primary verification for securing the driving safety of automated vehicles. It is expected to be utilized in the relevant studies as a basic study.
\end{abstract}

Keywords: automated vehicles; driving safety; driving handicap; AHP; factor analysis

\section{Introduction}

An automated vehicle performs self-driving by recognizing the surrounding environment through a sensor attached to its body and is expected to lead to various social benefits and impacts once introduced [1-4]. With automated driving technology already applied and utilized in vehicles driving on actual roads based on automated driver assistance systems (ADAS) technology, the anticipation for the automated vehicles is on the rise [5-7].

Prior to automated vehicle introduction in the market, pilot tests on test drives and parts of the technology were being conducted to confirm the effects based on actual vehicle driving. However, numerous car accidents and fatal accidents occurred since the start of the test drive and the pilot test of these automated vehicles. In particular, the first pedestrian mortality accident by Uber in March 2018 turned out to be a casualty accident that clearly showed the limitation of recognition sensors and errors in the judgment algorithm of the automated vehicle's sensors [8]. Apart from these, it was confirmed that similar problems, such as recognition sensor error and the emergence of GPS shading etc., occurred during driving in interrupted traffic flow sections in urban centers other than in uninterrupted traffic flow sections [9].

After proposing an automated vehicle-related bill, the United States is leading automated vehicle technology development by permitting automated vehicles license issuance and test drives for the first time [10]. Among numerous states which enacted related laws, the Department of Motor Vehicles (DMV) in California is regulating the submission of Disengagement Reports on accidents or disengagement of the automated driving function which could occur during test drives. The report will be prepared to include the condition of accidents as well as the status of disengagement of the automated driving 
function, cause of the occurrence, and factors. It thus reviews the technical limitation of the vehicles and provides an analysis of external environmental factors that could cause problems in automated driving [11-16].

Both in Korea and foreign countries, various studies related to the driving safety of automated vehicles are being conducted by including the aforementioned report, as well as other studies utilizing the report. However, there are a lack of studies on situations or sections having unsecured safety during automated driving. Since level 3 automated vehicles have increased responsibility for driving, driver safety must be guaranteed. There are limitations on securing safety because there are many sections within urban centers where automated driving is impossible, and many difficult situations for driving due to various influence factors on roads [17].

Accordingly, before proceeding with the study from a perspective that analysis on sections and situations expected to have impacts on driving is necessary for securing the driving safety of automated vehicles, this study classified those sections and situations within the urban centers as "handicap sections", and "handicap situations", respectively. There is a previous study in some way analogous to handicap sections and situations. In a previous study, it refers to challenging sections as traffic circles and an s-curve, which exist in urban environments [18]. Likewise, we adopt these notions, and also consider expanding and subdividing the scope of these notions in this study as handicap sections and situations. To perform the analysis on the corresponding sections and situations, the sections and situations were deducted via the consideration of preceding studies and consultations. Analytic hierarchy process (AHP) analysis was then performed by experts in the field of automated vehicles to analyze the handicap factors impacting the driving safety of automated vehicles.

\section{Literature Review}

To secure the driving safety of automated vehicles, the National Highway Traffic Safety Administration (NHTSA) has announced concepts on Operational Design Domain (ODD) which sets environmental, infrastructural, and social factors for automated vehicles in the level of current development, and Object and Event Detection and Response (OEDR) which refers to collision scenarios for responding to potential risks through lane maintenance and law compliance etc. in the designed ODD [19]. Shladover, S. E. has mentioned contents on specifications that should be supported in V21, $12 \mathrm{~V}$ fields for the development of high-level automated vehicles, safe driving, as well as the significance of ODD, to propose external factors which could impact the driving safety of automated vehicles [20]. The proposed external factors are largely classified into behaviors of other vehicles, moving objects, and weather conditions. In a study conducted by Schoettle, B., from a perspective that external information should be accurately recognized for the safe driving of automated vehicles, an analysis was conducted on situations limiting the recognition functions of vision sensors including cameras, vision, Lidar, and Radar in charge of the part handling recognition. The analysis results proposed extreme weather conditions, physical obstructions on the sensor surface, a darkness or glare phenomenon, physical obstructions, and dense traffic conditions as the situations having recognition limiting problems [9].

Additionally, in the U.S, the California DMV which leads the development of automated vehicles and the establishment of relevant policies in regulating the submission of Disengagement Reports on accidents during test drives of automated vehicles, or automated driving system disengagements [11]. The submission of this report is recommended by state governments to secure the driving safety of automated vehicles as well as to secure the safety of automated driving systems. Actual accident occurrences of automated vehicles can be confirmed via these reports. In a study conducted by Dixit V. V. et al., factors impacting the disengagement of automated mode situations during test drives of automated vehicles were confirmed to estimate a necessary reaction time during disengagement. For this purpose, DMV reports were utilized in analyzing accidents and accident-causing factors which occurred during the test drives, and the necessary time for responding to the disengagement of the automated mode was proposed as $0.83 \mathrm{~s}$. However, since the response time is affected by the hierarchy 
(type) of roads and the driving distance of the vehicle, response time increases as the driving distance of the vehicle increases. Furthermore, the study claimed that the safety (reliability) of the vehicle could be secured by sufficient driving experience [12].

Lv. C. et al. utilized the reports to analyze the disengagement of automated driving systems during test drives as well as factors impacting the disengagement of automated driving systems. The influence factors were largely classified into system factors such as Hardware $(\mathrm{H} / \mathrm{W})$, Software $(\mathrm{S} / \mathrm{W})$, and other influence factors. The external factors that were not system-related were classified into location, weather, and road surface conditions [13]. Yun H. N. et al. analyzed the disengagement of automated mode and its causes from the perspective of the driver, vehicle, and environment, which are the three factors of road traffic. The analysis results selected the automated driving system as the major cause for the disengagement of automated mode, and defects of the surrounding environment including recognition sensors were confirmed to be a vehicle factor for its cause. Among the external environmental factors, abrupt action around roads, construction, or accident sections were identified to be the main causes of disengagement. The emergencies based on control transfer were set to vehicle factors, failures of sensors and positioning modules, and ODD deviating [14]. In a study conducted by Favarò, F. et al., the existing California DMV data were utilized to analyze factors by situation impacting on the disengagement of automated mode, and the disengagement of automated mode by the manufacturer based on the factors, to analyze characteristics and influence factors of the disengagement of an automated mode of automated vehicles. The study classified the factors impacting on the disengagement of automated mode into system failure, external conditions, other factors, and human factors. Each factor was classified into subclasses, and according to the number of occurrences. The analysis results showed that the system failures were the largest impacting factors, and for non-vehicle factors, human and external factors impacted on the disengagement of automated mode. Among the external factors, it was revealed that lanes had the largest impact on the disengagement of automated mode, followed by other external factors including construction zones, road conditions, etc. As for weather conditions, since factors such as snow or wet road conditions were not classified as disengagement factors to be reported to the DMV, the study implied that consideration on these matters was necessary. Besides, the study also stated that the classification of manual and automatic disengagement situations was necessary for the disengagement of automated mode, and that common factors of disengagement of automated mode among reinvestigations should be categorized and defined [15]. Wang. S. and Li. Z. performed a statistical analysis that utilized actual test drive data to analyze the causes and influence factors of the disengagement of automated mode. This study classified the causes of the disengagement of automated mode into perception, planning, and control issues, and the frequency of accidents per individual factor was analyzed. Furthermore, a Tree structure was utilized to analyze the impact of the driving road type, and the number of attached sensors (LiDAR, radar, camera) on automated mode. The analysis results revealed that planning issues (undesired behaviors from road users) were the factors with the greatest impact on the test drives on current public roads. Also, the number of radars and LiDAR installed in vehicles played a role in the causes for the disengagement of automated mode. As such, the study stated that for reducing the disengagement of automated mode and improving the automated driving system (ADS), it is necessary to install at least five radars and three LiDAR. As for planning issues, the study also proposed that control transfer should be done within $0.5 \mathrm{~s}$ [16].

In Korea, studies on improving road facilities were conducted as a part of a study for securing the driving safety of automated vehicles. A study conducted by KICT and SANE analyzed the recognition of environments and major facilities where limitations on recognition occurred on automated vehicle sensors, to define requirements for improving road facilities. The analysis results confirmed that lanes and road signs were the major facilities impacted by sensor recognition. The analysis showed that factors such as nighttime rain conditions, direct sunlight or backlight, poor lane markings, etc. impacted on recognition [21]. Park and Yun performed a priority analysis utilizing AHP on factors (facilities) which configured road conditions, which showed that the safety of vehicles could be secured if road conditions were precisely recognized during the driving of the automated vehicle. The study results 
revealed that these factors had the highest priorities in the following order: traffic flow managing infrastructure in infrastructure, barriers in individual road infrastructure constituting infrastructure, and traffic lights. Accordingly, the study derived a conclusion that information on spaces where vehicles drive, and driving route should be recognized in advance to secure the safety of automated vehicles [22].

The summary of factors from previous literature reviews is presented in Tables 1 and 2. These consist of external elements and factors causing disengagement.

The result of considering the precedent studies related to the driving safety of automated vehicles can be summarized as follows. First, it was confirmed that to secure the driving safety of the vehicle within a drivable range (ODD) based on the technical level of the automated vehicle, consideration of various external environmental factors was required. In addition, it was also confirmed that the consideration of situations where limitations on sensor recognition occur, or other external factors impacting on recognition, was required since automated vehicles operate by utilizing sensors. Second, it was confirmed that a study utilizing data of the Disengagement Reports recommended by the CA DMV is being conducted on situations with disengagements and influence factors. Through this, it was confirmed that an analysis of factors impacting on driving and accidents of the actual vehicle is required.

As a result of considering the precedent studies, it was concluded that a study is required to be conducted on situations and sections with driving handicaps due to the deterioration of the driving safety of automated vehicles. For the analysis, this study aimed to derive potential handicap situations and sections during the time of urban center driving and set subclasses (situations and sections) constituting those. In addition, it aimed to select a priority through AHP investigation to derive situations and sections that are to be reviewed primarily for the driving of automated vehicles in urban centers.

Table 1. Classification of External Factors.

\begin{tabular}{|c|c|c|}
\hline Author & Factors & Description \\
\hline \multirow{6}{*}{ Dixit V. V. et al., (2016) } & System Failure & $\begin{array}{l}\text { Failure in detection technology, communications break down, } \\
\text { improper sensor readings, map or calibration issues, errors in } \\
\text { data reception }\end{array}$ \\
\hline & Driver Initiated & $\begin{array}{l}\text { Take control of the vehicle immediately, discomfort with the } \\
\text { autonomous mode }\end{array}$ \\
\hline & Road Infrastructure & $\begin{array}{l}\text { Improper detection of traffic lights, improper lane marking, } \\
\text { holes, bumps }\end{array}$ \\
\hline & Other Road Users & $\begin{array}{c}\text { Cyclists, pedestrians, emergency vehicles, other drivers } \\
\text { driving recklessly }\end{array}$ \\
\hline & Construction Zone & Construction activities, lane changing in heavy traffic \\
\hline & Weather & Rain, Sun glare \\
\hline \multirow{3}{*}{ Schoettle, B. (2017) } & $\begin{array}{l}\text { Extreme weather or other degraded } \\
\text { environmental conditions }\end{array}$ & Heavy rain, snow, or fog \\
\hline & Large physical obstructions & Buildings, terrain, heavy vegetation. \\
\hline & Dense traffic & $\begin{array}{l}\text { Interferes with or reduces the line of sight for human vision } \\
\text { and all basic AV sensors (cameras, radar, lidar) }\end{array}$ \\
\hline \multirow{3}{*}{ Lv, C. et al., (2018) } & Location & Street, Interstate way, Freeway/highway \\
\hline & Weather & Sunny, Cloudy, Rainy \\
\hline & Road Surface Conditions & $\begin{array}{l}\text { Dry, Wet, Poor road condition w/holes or bumps, Poor } \\
\text { lane markings }\end{array}$ \\
\hline Shladover, S. E. (2018) & Behaviors of Other Vehicles & $\begin{array}{l}\text { Entering from the blind driveway, Violating traffic low, Law } \\
\text { enforcement }\end{array}$ \\
\hline
\end{tabular}


Table 2. Classification of Factors of Disengagement.

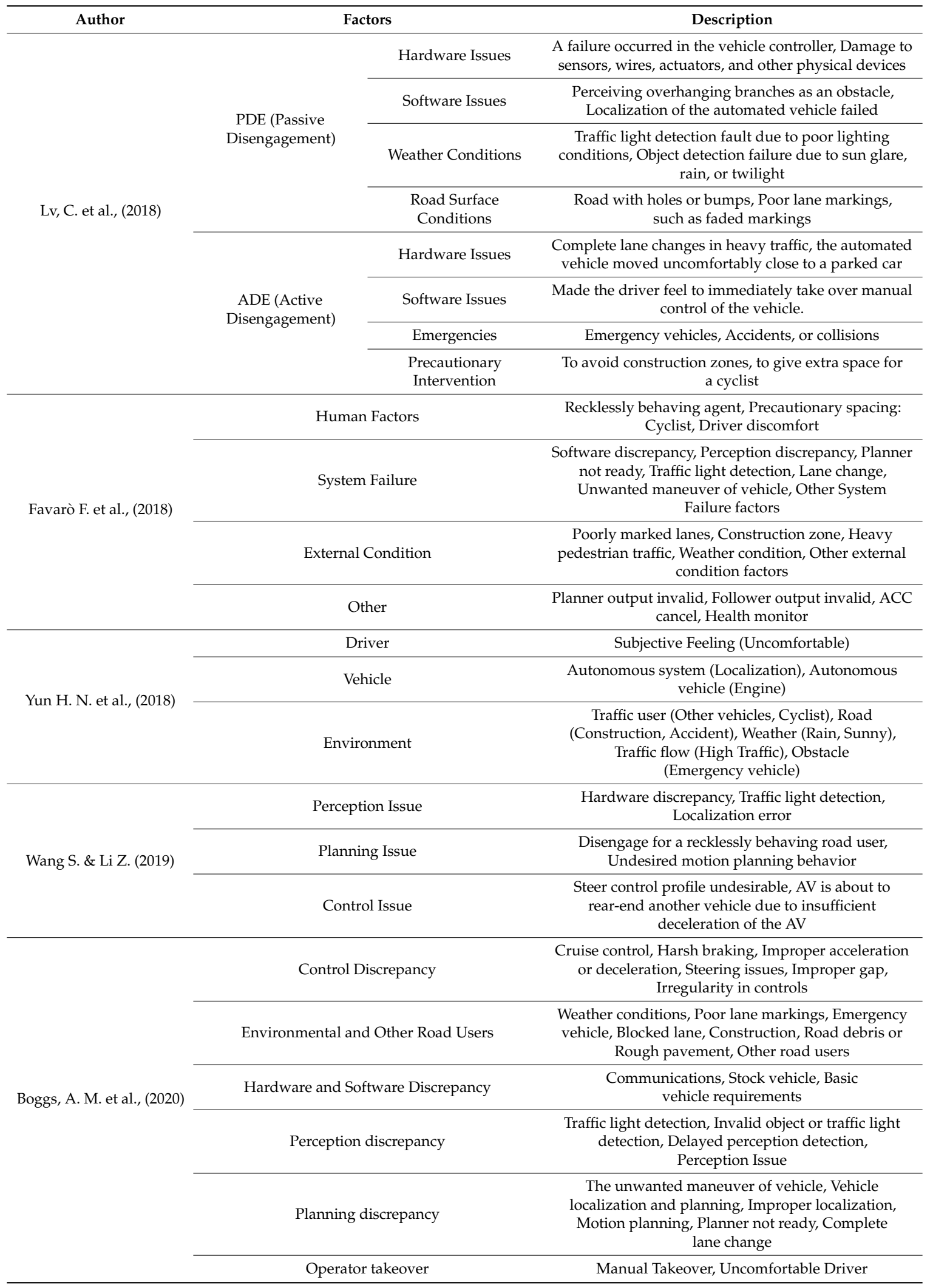




\section{Methodology}

This study aimed to set the driving handicap sections and situations that could occur during actual driving, and analyze priorities among factors constituting each section and situation to derive the driving handicap sections and situations to be primarily reviewed.

For this purpose, this study utilized consultations with experts as well as the previously reviewed results of the precedent studies to set handicap sections and situations, designated factors constituting the corresponding sections and situations, and derived priority through AHP analysis. AHP (analytic hierarchy process) is a multi-criteria analysis methodology used for systematic evaluation if there are multiple objectives of decision-making or evaluation criteria. This process stratifies the decision-making criteria, breaks them down to main factors and subclasses, and estimates their significance through a pairwise comparison among the factors [23]. Furthermore, AHP is able to structuralize problems, utilize models, and derive a relative significance per factor to obtain a quantitative result. It also has the advantage of being utilized in solving decision-making problems [24,25]. Therefore, the AHP analysis was determined to be suitable for the analysis on the set handicap sections and situations in this study.

\subsection{Handicap Sections and Situations Setting}

To set the handicap sections and situations of automated vehicles, and designate their subclasses, opinions on manufacture, test drive, and GPS navigation etc. of automated vehicles were gathered through consultations with major experts in the sensor field. The consultation was carried out by classifying the main contents largely into the manufacturing of automated vehicles, items related to driving handicaps, and other items.

\section{Result of Consultation with Experts}

The contents of the consultation with experts can be summarized as follows. First, as for the manufacture of automated vehicles, existing road information was obtained around the scope of the sensors. However, it was confirmed that the current trend for obtaining the information was via V2X technology. Furthermore, the video information of a vehicle relies more on cameras than radar, and this was revealed to be due to fine video processing in tunnel sections where illumination changes, as well as during nighttime driving. Second, the contents related to the driving handicap of automated vehicles were the opinions obtained from the experts while they were performing vehicle test drives.

The opinions obtained during the test drive were summarized as about situations where GPS signal information reception was impossible in regions with a concentration of high-rise buildings, where Lidar was unable to recognize conditions due to the color of the vehicle in front and from weather, where it was unable to detect moving objects such as pedestrians or bicycles, and where differences occurred in the recognition distance of Radar based on a test environment (like illumination differences). Furthermore, it was implied that in long tunnel sections where receiving GPS signals became difficult due to weakened signals, and where the vehicle drove onto off-roads without painted line markings, safety deteriorated. In addition to this, the information required for the driving of autonomous vehicles, excluding signal information, is the location data of all vehicles and the operation information (driving paths, driving habits, etc.) of general vehicles. Also, they emphasized the need for infrastructures that can provide this information.

As a result of the consultation, it was determined that the following items should be considered to set the sections and situations. First, it should include driving handicap sections and situations where sensor failures occur, as well as the external environment considered to cause the failures. Second, the driving handicap factors due to the characteristics of urban center roads (high-rise buildings, and moving objects around the roads) should be reflected in the item. The opinions of the experts we had consultations with make up the content related to handicaps that occurred during test drives in urban centers. Thus, it was determined that such content should be reflected in the item on driving in urban centers in the future. 


\subsection{Item Design Based on Handicap Sections and Situations}

To set the driving handicap sections and situations of automated vehicles, and designate subclasses, the following assumptions were made before deriving the handicap sections and situations through their influence factors obtained in consideration of driving safety-related precedent studies, and through the result of an expert consultation.

First, the handicap situations and sections were set as sections and situations with expected deteriorated driving safety due to external factors, and not due to problems due to vehicles during operation, as they were lower-level concepts of the aforementioned ODD. ODD includes the same restrictive situation with road types and environmental conditions where the automated vehicle can drive, and it is an operating condition designed to allow for the proper operation of the automated driving system. OEDR refers to a scenario responding to a risky situation that could occur according to ODD. The driving handicap to be derived from this study is that of a situation which could occur due to external factors when the automated vehicle drives in an urban center, or a section where driving is difficult. Therefore, it was determined to be applied as a lower-level concept of ODD which sets a drivable range for the automated vehicle.

Second, it was assumed that factors constituting the handicap sections and situations were mutually exclusive. It is expected that complex effects other than environmental factors will be present due to effects among the factors on roads on which automated vehicles will drive. However, considering the complexity between the time factor and other factors, it was determined that the objective of this study should be changed to deriving all factors impacting automated vehicles, and not only the factors setting the handicap sections and situations. Accordingly, this study limited its scope to driving handicap sections and situations able to occur in urban centers and assumes that the components have a mutually exclusive relationship among them.

Third, it was assumed that the driving handicap environment, where driving safety deteriorates and automated driving becomes difficult, has a dot-line-dot relationship. Figure 1 shows the relationship diagram of the driving handicap environment.

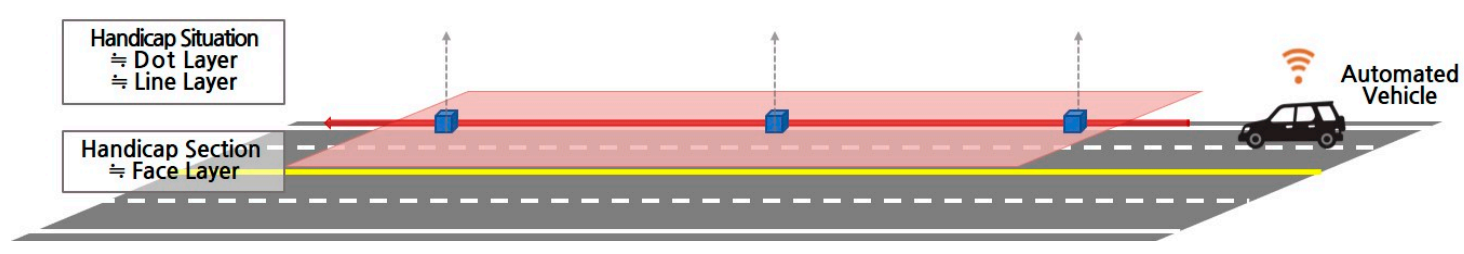

Figure 1. Relationship between Handicap Section and Situation.

The handicap sections and handicap situations were defined by reflecting the previously assumed items and the characteristics of the driving handicap environment. A handicap section is a section where a physical influence is present on the surface within the driving environment (space) of the automated vehicle and was defined as a section with influences such as limitations in recognizing lanes and configured with the factors impacting the driving on the surface. A handicap situation is a situation impacting instantaneously or temporarily at the time of driving the automated vehicle such as with lines and dots and was configured with situational factors causing accidents including both one-time and sudden accidents, and environmental factors. Table 3 summarizes the handicap section, handicap situation, and subclasses per situation designed accordingly. 
Table 3. The Factor Definition of Handicap Section and Situation.

\begin{tabular}{|c|c|c|}
\hline & Variable & Description \\
\hline \multirow{8}{*}{ 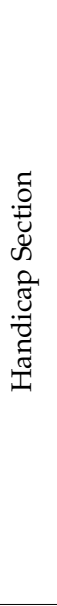 } & $\begin{array}{l}\text { Areas with Skyscrapers } \\
\text { (High-rise buildings) }\end{array}$ & $\begin{array}{l}\text { Lower sections of the structure, such as overpasses, where high-rise } \\
\text { buildings are concentrated, such as urban areas or some } \\
\text { commercial areas }\end{array}$ \\
\hline & Children and Senior Protect Zone & $\begin{array}{l}\text { Lane paint, linear, speed limit change section for children and } \\
\text { senior citizen }\end{array}$ \\
\hline & Section with Poor Lane Condition & $\begin{array}{l}\text { Lane loss due to wear and tear, brightness difference due to lane } \\
\text { repainting, existing lane changed due to lane increase and decrease }\end{array}$ \\
\hline & Construction Section & Spot or sections where construction signs and traffic cones are installed \\
\hline & Merging section & Areas with frequent intersections or lane changes \\
\hline & Yellow Light Dilemma Section & $\begin{array}{c}\text { An area on the high-speed intersection approach, where vehicles neither } \\
\text { safely stop before the stop line nor proceed through the intersection } \\
\text { during the amber interval }\end{array}$ \\
\hline & Off-road section & The off-road segment with no lanes and no road maintenance \\
\hline & Tunnel Section & Tunnel sections within city and highway paths \\
\hline \multirow{8}{*}{ 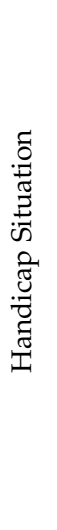 } & Direct Sunlight & Light bleeding and recognition error due to light reflection \\
\hline & Heavy Rain and Snow & $\begin{array}{l}\text { Road flooding due to heavy rain, road freezing due to heavy snowfall } \\
\text { and unrecognized lanes }\end{array}$ \\
\hline & Fine dust and Fog & $\begin{array}{l}\text { The situation where the recognition sensor and recognition distance } \\
\text { cannot be secured due to fine dust and fog }\end{array}$ \\
\hline & Stopping of Large Vehicle & $\begin{array}{l}\text { The occurrence of sign and traffic light obstruction due to the stopping } \\
\text { of heavy vehicles }\end{array}$ \\
\hline & Driving of Emergency Vehicle & An emergency vehicle is driving or approaching to Automated vehicle \\
\hline & Falling Objects on Road & Objects dropped on the road due to poor loading or other causes \\
\hline & Abrupt Action Around Road & $\begin{array}{l}\text { Incursions such as sudden moves, unauthorized crossings of } \\
\text { pedestrians around a road, or abrupt behavior of dogs or wild animals }\end{array}$ \\
\hline & Pothole & Pothole occurred on the road \\
\hline
\end{tabular}

\section{Result of AHP Analysis}

\subsection{Analysis Summary}

A survey sheet was prepared by utilizing the previously deducted factors for AHP analysis. The survey was given to 23 experts in the automated vehicle-related field, and the survey sheet was configured to allow describing sections or situations where the driving handicap occurs based on the experts' perspectives, apart from the previously derived factors. Furthermore, a weight analysis was performed after confirming that the estimated values of CI, CR from the AHP analysis result satisfied the condition of less than 0.1 , which was the standard value. Priority per factor was then designated by utilizing the relevant results. The outline of the AHP survey is summarized in Table 4 .

Table 4. Analytic Hierarchy Process (AHP) Survey Summary.

\begin{tabular}{|c|c|c|c|}
\hline Classification & \multicolumn{3}{|c|}{ Description } \\
\hline Survey Period & \multicolumn{3}{|c|}{15 September 2019 30 October 2019 (for 45 days) } \\
\hline Sample & \multicolumn{3}{|c|}{23} \\
\hline \multirow{5}{*}{$\begin{array}{l}\text { Respondent's Career } \\
\text { field (Number of experts) }\end{array}$} & \multirow{2}{*}{ Mechanical Engineering } & Vehicle Control & 5 \\
\hline & & Vehicle Sensor & 3 \\
\hline & \multirow{2}{*}{ Transportation Engineering } & Road Infrastructure & 3 \\
\hline & & Management of Traffic Flow & 4 \\
\hline & \multicolumn{2}{|c|}{ Transportation Planning } & 8 \\
\hline
\end{tabular}




\subsection{Result of Weighted Value Estimation}

Before designating the priority per subclass of the driving handicap sections and handicap situations, this study aimed to first perform a factor analysis of the handicap sections and situations. For this purpose, the main factors were set as hierarchy 1 , and the subclasses constituting the main factors as hierarchy 2 through a hierarchy setting. The AHP analysis was performed according to the previously classified hierarchy.

\subsubsection{Main Factors (Hierarchy 1)}

As a result of estimating the weighted values of the driving handicap sections and handicap situations, the weighted value of the handicap situations was 0.64 , which was higher than that of the handicap sections. This implies that preventive measures should be taken for the handicap situations, and not the handicap sections, to improve the driving safety of the automated vehicle. The reason for this is considered to be because, as driving safety decreases due to the variability and suddenness possessed by handicap situations, one tends to feel that it has a greater risk than the handicap sections, and at the same time, greater risk in the aspect of potential accidents as well. The weight analysis result of the main factors is shown in Table 5.

Table 5. Result of Weight Analysis (1) Main Factor (Hierarchy 1).

\begin{tabular}{cc}
\hline Variable & Weight (Eigen Vector) \\
\hline Handicap Section & 0.3538 \\
Handicap Situation & 0.6462 \\
\hline
\end{tabular}

\subsubsection{Handicap Section (Hierarchy 2)}

Second, the result of analyzing the significance per subclass through the factor analysis within the handicap section is as follows. The analysis showed that the weighted value (0.1567) of the merge sections among the subclasses of the handicap sections were the highest, followed by in section order with poor lane conditions (0.1482), construction sections (0.1433), and yellow light dilemma sections (0.1413). The factors which are analyzed to have higher significances are generally the sections where conflicts occur between vehicles due to the distinctiveness of the section even in the current traffic situation. Thus, driver attention and judgment are signified in the section. Such results are considered to be derived because this section is where driving handicaps could occur if the automated vehicle drives using a general driving algorithm. As for lanes, a great deal of information is required for automated driving. Thus, the high significance derived for the lane is determined to be due to a high possibility of driving handicap occurrence based on poor lane marking colors. The results for the construction section and the yellow light dilemma zone are determined to be due to an impossibility of pre-recognition, and uncertainty of whether the automated vehicle could instantaneously decide the status of driving in the same way that a regular driver does. The weight analysis result of the subclass of the handicap section is shown in Table 6 . 
Table 6. Result of Weight Analysis (2) Handicap Section (Hierarchy 2).

\begin{tabular}{ccc}
\hline Variable & Weight (Eigen Vector) & Rank \\
\hline Areas with Skyscrapers (High-rise buildings) & 0.0771 & 8 \\
\hline Children and Senior Protect Zone & 0.1101 & 6 \\
\hline Section with Poor Lane Condition & 0.1482 & 2 \\
\hline Construction Section & 0.1433 & 3 \\
\hline Merging section & 0.1567 & 1 \\
\hline Yellow Light Dilemma Section & 0.1413 & 4 \\
\hline Off-road section & 0.1094 & 7 \\
\hline Tunnel Section & 0.1139 & 5 \\
\hline
\end{tabular}

\subsubsection{Handicap Situation (Hierarchy 2)}

Third, the result of analyzing the significance per subclass through the factor analysis in the handicap situation is as follows. Among the subclasses of handicap situations, the significance of abrupt actions around roads (0.2191) was confirmed to be the highest, followed by heavy rain and snow (0.1576), falling objects on roads (0.1494), and the driving of emergency vehicles (0.1105). Among all subclasses, the significance of abrupt actions around roads was derived as the highest, and this was considered to be because it was recognized as the major factor causing driving handicaps during automated driving. The automated vehicle drives by recognizing risk factors towards the front and on the driving route in advance through sensors. However, abrupt situations occurring suddenly on the road or in its surroundings can be applied as a large risk factor to not only the driving safety of the automated vehicle, but also to all vehicles on the road, pedestrians, and otherwise. Therefore, such results were obtained accordingly. As for heavy rain and snow factors, if a handicap occurred in environmental recognition (lane recognition, etc.) through sensors, and the automated vehicle caused an accident, there would be a high risk of a secondary accident. Therefore, it is considered to have the second-highest significance. The reason for the high significance of this factor of falling objects on roads is considered to be because of the presence of an effect, such as causing a secondary accident, etc., in the situation caused by the aforementioned heavy rain and snow factors due to sudden falling objects on the road. As for emergency vehicles, if the emergency vehicle suddenly appears while the driving route of the vehicle is not previously given, an error might occur in the driving judgment algorithm of the automated vehicle. The weight analysis result of the subclass of the handicap section is shown in Table 7.

Table 7. Result of Weight Analysis (3) Handicap Situation (Hierarchy 2).

\begin{tabular}{ccc}
\hline Variable & Weight (Eigen Vector) & Rank \\
\hline Direct Sun light & 0.079 & 7 \\
\hline Heavy Rain and Snow & 0.1576 & 2 \\
\hline Fine dust and Fog & 0.1029 & 6 \\
\hline Stopping of Large Vehicle & 0.0764 & 8 \\
\hline Driving of Emergency Vehicle & 0.1105 & 4 \\
\hline Falling Objects on Road & 0.1494 & 3 \\
\hline Abrupt Action Around Road & 0.2191 & 1 \\
\hline Pothole & 0.1051 & 5
\end{tabular}




\subsection{Priority Designation Based on the Result of Weighted Value Estimation}

Priority was designated based on the results of the weighted value estimation previously obtained. It was designated by utilizing the value deducted by multiplying the weighted value per major factor (hierarchy 1) to the weighted value of the subclass (hierarchy 2) constituting the major factor. According to the results of priority designation, it was revealed that the priority given to abrupt action around roads (0.142) of the handicap situations with the highest significance among the subclasses was the highest. Next, the analysis showed the greatest significance in the following order: heavy rain and snow (0.102), falling objects on the road (0.097), and emergency vehicle driving (0.071) for the subclasses of the handicap situation; merge sections (0.055), sections with poor lane conditions (0.052), and yellow light dilemma sections (0.050) in the handicap section. As a result of considering an overall priority ranking, it was confirmed to be necessary to first consider situations where driving handicaps occur due to the factors in the order of abrupt action around roads, heavy rain, and snow, and falling objects on the road. Furthermore, it is considered to be necessary to accompany considerations on merge sections and sections with poor lane conditions which might impact on the recognition and judgment during the operation of automated vehicles. The result of weight analysis and priority designation of all factors is shown in Table 8.

Table 8. Result of Weight Analysis and Priority Designation (4) All Factors.

\begin{tabular}{|c|c|c|c|c|c|c|}
\hline $\begin{array}{l}\text { Main Factor } \\
\text { (Hierarchy 1) }\end{array}$ & Weight (a) & Sub Class (Hierarchy 2) & Weight (b) & $\begin{array}{l}\text { Definitive Weight } \\
\qquad(\mathbf{a} \times \mathbf{b})\end{array}$ & $\begin{array}{c}\text { Rank in Sub } \\
\text { Class }\end{array}$ & Final Rank \\
\hline \multirow{8}{*}{ Handicap Section } & \multirow{8}{*}{0.354} & $\begin{array}{l}\text { Areas with Skyscrapers } \\
\text { (High-rise buildings) }\end{array}$ & 0.0771 & 0.0273 & 8 & 16 \\
\hline & & $\begin{array}{l}\text { Children and Senior } \\
\text { Protect Zone }\end{array}$ & 0.1101 & 0.0390 & 6 & 14 \\
\hline & & $\begin{array}{l}\text { Section with Poor } \\
\text { Lane Condition }\end{array}$ & 0.1482 & 0.0524 & 2 & 8 \\
\hline & & Construction Section & 0.1433 & 0.0507 & 3 & 10 \\
\hline & & Merging section & 0.1567 & 0.0554 & 1 & 7 \\
\hline & & $\begin{array}{c}\text { Yellow Light } \\
\text { Dilemma Section }\end{array}$ & 0.1413 & 0.0500 & 4 & 11 \\
\hline & & Off-road section & 0.1094 & 0.0387 & 7 & 15 \\
\hline & & Tunnel Section & 0.1139 & 0.0403 & 5 & 13 \\
\hline \multirow{8}{*}{ Handicap Situation } & \multirow{8}{*}{0.646} & Direct Sun light & 0.0790 & 0.0510 & 7 & 9 \\
\hline & & Heavy Rain and Snow & 0.1576 & 0.1018 & 2 & 2 \\
\hline & & Fine dust and Fog & 0.1029 & 0.0665 & 6 & 6 \\
\hline & & Stopping of Large Vehicle & 0.0764 & 0.0494 & 8 & 12 \\
\hline & & $\begin{array}{c}\text { Driving of } \\
\text { Emergency Vehicle }\end{array}$ & 0.1105 & 0.0714 & 4 & 4 \\
\hline & & Falling Objects on Road & 0.1494 & 0.0965 & 3 & 3 \\
\hline & & $\begin{array}{l}\text { Abrupt Action } \\
\text { Around Road }\end{array}$ & 0.2191 & 0.1416 & 1 & 1 \\
\hline & & Pothole & 0.1051 & 0.0679 & 5 & 5 \\
\hline
\end{tabular}

\section{Discussion}

The result of analyzing the sections and situations where the driving handicap of the automated vehicle occurs can be summarized as follows. First, among the handicap sections and situations where the driving handicaps occur, the significance of handicap situations involving suddenness and variability was analyzed to be high. As mentioned previously, this is considered to emphasize first securing driving safety on handicap situations where the automated vehicle cannot recognize the situation in advance, and the situation occurrence uncertainty is high.

As a result of designating priority based on the weighted value analysis result of the subclasses constituting the major factors, it was revealed that the priority given to the factor of abrupt action around roads was the highest. This is considered to be because automated vehicles cannot recognize 
abrupt actions around roads in advance, and if this situation occurs, it will impact not only on the automated vehicle but also other interested parties on the road as well as near automated vehicles, which leads to an increased seriousness of the situation. The priority given to environmental factors such as weather or atmospheric environment was analyzed to be high (heavy rain and snow, fine dust factors). This is considered to be because environmental factors reduce the accuracy and recognition capability of vehicle sensors and cause the driving handicap. Furthermore, this study derived the possibility of driving handicaps caused by the section having the potential to impact surrounding vehicles (such as merging sections), and lane conditions which are utilized as essential information for the operation of an actual vehicle. Apart from these, it was confirmed that the significance of the factors which are expected to impact the recognition and judgment phases of the automated vehicle was high. To secure the driving safety of automated vehicles, it is considered to be necessary to secure the safety of the driving handicap environment, which includes the previously derived factors.

Apart from the previously analyzed results, the result of converging opinions on driving handicap sections and situations from the experts is as follows. The handicap sections viewed by experts included narrow driving sections of side streets, a section where a rapid curvature rate occurs, and passing and climbing sections. For handicap situations, it was confirmed to be necessary to secure driving safety in situations with illegally parked vehicles on both sides of one-lane roads, line crossing by vehicles driving in the next lane, sudden braking and accidents by the vehicle in front, and passing a turn left with a caution section and a roundabout. After reviewing the opinions from the experts, it was determined that an additional review is required on the sections and situations impacting the recognition and judgment of automated vehicles, which might occur in actual driving just as in the previously designated sections and situation.

\section{Conclusions}

This study derived handicap sections and situations where driving handicaps occur and performed AHP analysis utilizing environmental factors constituting the handicap sections and situations, to secure the driving safety of automated vehicles. The results of the study can be summarized as follows. First, it was revealed that among the handicap sections and situations, the handicap situations should be primarily reviewed. It was confirmed that abrupt actions around roads had a high significance. Second, the analysis showed that in the handicap situations, the environmental factors (heavy rain and snow, fine dust), falling objects on the road, merging sections of handicap sections, and poor lane conditions had a high significance. This result indicates that the factors impacting the recognition and judgment functions of automated vehicles are the handicap situations and sections which should be primarily reviewed for securing driving safety, and it can be judged that empirical research on the handicap situations and sections should be conducted through actual test driving.

The limitations of this study can be summarized as follows. As an opinion additionally derived from this analysis, considerations on various situations should be made. Furthermore, since it was assumed that the factors had a mutually exclusive relationship, the lack of considering potential situations caused by a combined application can be regarded as a limitation. For instance, the time factor may impact driving handicaps with a combined application with the factors utilized at the time of analysis, which leads to the necessity of consideration. Besides, since the development phase of automated vehicle technology was limited to its initial phase when the assumption for the driving handicaps was made, there is a limitation that the potential driving handicap caused by the technical level could not have been considered overall.

Also, it is necessary to consider adding the situation and combinations which might occur among the factors by the technical phase of automated vehicles. Furthermore, it needs to discuss the definition of handicap sections and situations. In this study, we defined handicap sections and situations in which automated driving was difficult and we have used this definition in Korea. However, there is a conflict because a similar term is defined as challenge sections in the existing literature [18]. For example, the previous study defined challenging sections as the traffic circles and s-curve, which are specific 
sections. Thus, there is a difference with the handicap defined in this study, hence the need for a discussion establishing the terminology.

Additionally, since driving handicaps and individual factors are proposed in a limited way, it is determinable to be necessary to prepare and propose a checklist that could resolve the handicap problems through an overall review of potential situations. Furthermore, to solve driving handicaps, it is also determinable to be necessary to consider the direction of supporting an automated cooperation function via supporting existing road infrastructure and developing new road infrastructure. Since automated vehicles drive together with regular vehicles in the initial phase of their introduction, it is expected that driving through $\mathrm{V} 2 \mathrm{~V}$ would have limitations. To resolve this and to secure driving safety, road infrastructure support is considered to be necessary $[3,26,27]$. For instance, for a situation where securing a clear view is difficult due to the emergence of blind spots created by street trees and stationary vehicles in an urban center, it can be determined that cameras for securing a clear view or the development of infrastructure which can detect moving objects around roads is necessary. Furthermore, it is necessary to consider factors causing actual impacts and variables on roads through empirical studies to derive factors by road environments in Korea, and define driving handicaps accordingly.

Author Contributions: Conceptualization, C.-G.R. and I.-J.I.; methodology, C.-G.R. and I.-J.I.; formal analysis, C.-G.R. and I.-J.I.; visualization, C.-G.R. and I.-J.I.; writing-original draft preparation, C.-G.R. and I.-J.I.; writing - review and editing, I.-J.I.; supervision, I.-J.I. All authors have read and agreed to the published version of the manuscript.

Funding: This research was funded by Ministry of Land, Infrastructure and Transport Affairs of Korean government (MOLIT), grant number 20PQOW-B152473-02.

Conflicts of Interest: The authors declare no conflict of interest.

\section{References}

1. National Highway Traffic Safety Administration. National Motor Vehicle Crash Causation Survey; Report DOT HS 811 059; U.S. Department of Transportation: Washington, DC, USA, 2008.

2. Fagnant, D.; Kockelman, K. Preparing a nation for autonomous vehicles: Opportunities, barriers and policy recommendations. Transp. Res. Part A 2015, 77, 167-181. [CrossRef]

3. Labi, S.; Saeed, T.U.; Volovski, M.; Alqadhi, S. An exploratory discussion of the Impacts of Driverless Vehicle Operations on the Man-Made Environment. In Proceedings of the 1st International Conference on Mechanical and Transportation Engineering, Kuala Lumpur, Malaysia, 23-25 April 2015.

4. Im, I.; Lee, J.; Hwang, K. Legal Issues Related with Autonomous Vehicle Operation. J. Transp. Res. 2016, 23, 75-91.

5. Young, M. Ergonomics issues with advanced driver assistance systems (ADAS). Automot. Ergon. 2012, 810, $55-76$.

6. Ziebinski, A.; Cupek, R.; Grzechca, D.; Chruszczyk, L. Review of advanced driver assistance systems (ADAS). AIP Conf. Proc. 2017, 1906, 120002.

7. Orlovska, J.; Novakazi, F.; Lars-Ola, B.; Karlsson, M.; Wickman, C.; Söderberg, R. Effects of the driving context on the usage of Automated Driver Assistance Systems (ADAS)-Naturalistic Driving Study for ADAS evaluation. Transp. Res. Interdiscip. Perspect. 2020, 4, 100093. [CrossRef]

8. National Transportation Safety Board. Preliminary Report Highway (HWY18MH010); Accident Reports; National Transportation Safety Board: Washington, DC, USA, 2018.

9. Schoettle, B. Sensor Fusion: A Comparison of Sensing Capabilities of Human Drivers and Highly Automated Vehicles; SWT-2017-12; University of Michigan, Transportation Research Institute: Ann Arbor, MI, USA, 2017.

10. Nevada Department of Motor Vehicles (Nevada DMV). Autonomous Vehicles. Available online: https://dmvnv.com/autonomous.htm (accessed on 20 June 2020).

11. California Department of Motor Vehicles (CA DMV). Disengagements Reports. Available online: https://www. dmv.ca.gov/portal/vehicle-industry-services/autonomous-vehicles/disengagement-reports (accessed on 20 June 2020).

12. Dixit, V.V.; Chand, S.; Nair, D.J. Autonomous Vehicles: Disengagements, Accidents and Reaction Times. PLoS ONE 2016, 11, e0168054. [CrossRef] [PubMed] 
13. Lv, C.; Cao, D.; Zhao, Y.; Auger, D.J.; Sullman, M.; Wang, H.; Dutka, L.M.; Skrypchuk, L.; Mouzakitis, A. Analysis of Autopilot Disengagements Occurring during Autonomous Vehicle Testing. IEEE/CAA J. Autom. Sin. 2018, 5, 58-68. [CrossRef]

14. Yun, H.; Kim, S.; Lee, J.; Yang, J. Analysis of Cause Disengagement Based on U.S. California DMV Autonomous Driving Disengagement Report. Trans. Korean Soc. Automot. Eng. 2018, 26, 464-475. [CrossRef]

15. Favarò, F.; Eurich, S.; Nader, N. Autonomous vehicles' disengagements: Trends, triggers, and regulatory limitations. Accid. Anal. Prev. 2018, 110, 136-148. [CrossRef] [PubMed]

16. Wang, S.; Li, Z. Exploring causes and effects of automated vehicle disengagement using statistical modeling and classification tree based on field test data. Accid. Anal. Prev. 2019, 129, 44-54. [CrossRef] [PubMed]

17. Roh, C. Configuration and Evaluation of Local Dynamic Map Platform for Connected Automated Driving in Urban Roads. J. Korean Soc. Transp. 2020, 38, 42-57. [CrossRef]

18. Sirkin, D.; Baltodano, S.; Mok, B.; Rothenbücher, D.; Gowda, N.; Li, J.; Martelaro, N.; Miller, D.; Sibi, S.; Ju, W. Embodied design improvisation for autonomous vehicles. In Design Thinking Research; Springer: Cham, Switzerland, 2016; pp. 125-143.

19. National Highway Traffic Safety Administration (NHTSA). Automated Driving Systems 2.0: A Vision for Safety; NHTSA: Washington, DC, USA, 2017.

20. Shladover, S.E. Practical Challenges to Deploying Highly Automated Vehicles. Key note. In Proceedings of the 6th NYC Symposium on Connected and Autonomous Vehicle, New York, NY, USA, 23-24 October 2018.

21. Korea Institute of Civil Engineering and Building Technology and SANE. Development of Smart Cooperative Driving Road System (2nd Research Report); Korea Institute of Civil Engineering and Building Technology and SANE: Ilsan, Korea, 2017.

22. Park, J.; Yun, D. The recognition Prioritization of Road Environment for Supporting Autonomous Vehicle. J. Korea Acad. Soc. 2018, 19, 595-601.

23. Saaty, T.; Erdener, E.R.E.N. A New Approach to Performance Measurement the Analytic Hierarchy Process. Des. Methods Theories 1979, 13, 62-68.

24. Park, H.; Ko, G.; Song, J. A Study on Multi-Criteria Analysis Method for Pre-Feasibility Study; Korea Development Institute: Sejong, Korea, 2001.

25. Hwang, K.; Song, J.; Kang, M.; Im, I. An Importance Analysis of the Korean Ethical Guideline for Automated Vehicle Using AHP Method. J. Korea Inst. Intell. Transp. Syst. 2020, 19, 107-120. [CrossRef]

26. Saeed, T.U. Road Infrastructure Readiness for Autonomous Vehicles; Chapter 6: Road Infrastructure and Design Readiness. Ph.D. Thesis, Purdue University Graduate School, West Lafayette, IN, USA, 2019.

27. Im, I.; Kim, Y. A Study on Social Perception on the Regulatory Information Service Diffusion of Traffic Facilities. J. Korea Inst. Intell. Transp. Syst. 2020, 19, 1-17. [CrossRef] 